\title{
Characterization of Process Air Emissions in Automotive Production Plants
}

J.B. D’Arcy, J. M. Dasch, A. B. Gundrum, J. L. Rivera, J. H. Johnson, D. H. Carlson, and J. W. Sutherland

\section{Supplementary Files}

\section{PROCESS DESCRIPTION}

\section{Casting - iron foundry melt/pour.}

Automotive engine blocks and heads are cast in this grey iron foundry. The charge material that produces the grey iron consists primarily of coke, limestone, and scrap metal. Molten material is poured into green sand molds, consisting of sand, bentonite clay, and seacoal. Cores are formed with sand and a phenolic resin binder, with the resin decomposing/combusting upon the introduction of molten iron into the mold. Two cupolas, one traditional gas fired and one an electric plasma-arc, operate at about $2400^{\circ} \mathrm{F}$ to provide the molten metal. The molten iron flows down launders into holding furnaces from which it is transported by overhead hot-metal cranes to the location where it is poured into rotary-pour machines, which transfer the molten metal to the flasks.

\section{Casting - iron foundry shakeout.}

Molten grey iron is poured into the green sand molds and cools following the removal of the cope (top of mold). The drag (bottom of mold) with the casting continues to the shakeout area where the casting is removed and shaken to remove residual sand. The majority of the shakeout process is automated and takes place using enclosed and ventilated equipment. General ventilation is prevalent and a combination of slot and canopy hoods is used in the casting removal area and in the inspection area following the automated shakeout. 


\section{Casting - aluminum lost foam.}

Aluminum engine blocks, heads, and sprocket supports are cast in this plant using the lost-foam process, which consists of pouring molten aluminum into flasks containing a polystyrene pattern packed into sand. Molten aluminum is poured into the flask and allowed to cool. A hood is mounted above the pour area. The cooling flasks move on an enclosed and ventilated conveyor for approximately 1 hour prior to removal of the casting. A robot dumps the casting and sand from the flask in an enclosed and ventilated booth. The used sand moves to a Didion drum maintained at a temperature of $650^{\circ} \mathrm{F}$. Dust collectors equipped with catalytic incinerators collect entrained fine particles from the sand and pyrolysis products and exhaust the cleaned air through the roof. A sand processor cools and sizes the cleaned sand from the Didion drum. Forty-five parts are produced per hour on four lines.

\section{Casting - aluminum diecast.}

In the diecast process, a steel die is sprayed with water, air, and a die release agent (DeltaCast 582 from Acheson), producing smoke in the process. Other chemicals used in the area include a die start-up lubricant (Chem Trend Die Lube RDL-5002) and a plunger tip lubricant (Acheson PL 2180 ). The die closes and 40 to 45 pounds of molten aluminum (Al 380 alloy) at $1230^{\circ} \mathrm{F}$ is injected into the die under 4000-psi pressure. After cooling, the die opens, the casting is expelled, and the operator removes excess metal from the casting. The die area of the machine is equipped with a canopy hood for die lube and smoke control. The cycle time for each transmission case was about 110 seconds. Eighteen diecast units produced transmission cases in three-shift operation.

\section{Machining - wet machining.}

Cast aluminum (Al 319 alloy) L850 blocks were machined in a 38,500- $\mathrm{ft}^{2}$ area on Thyssen Huller machines and $\mathrm{L} 850$ heads were machined in a 36,000- $\mathrm{ft}^{2}$-area on Grob machines. Both areas operated on one 10-hr shift with target production of 821 heads and 313 blocks. All machines were fully enclosed. The machine enclosures were ventilated to five Monroe spiral tube mist collectors. The machining fluid was a Castrol WS3-908E semi-synthetic fluid used at 10\% concentration. Separate 80,000-gal sumps fed the block and head areas. Two Durr washers, 
located in the block area, had a 2200-gal capacity and used Permatreat 435 cleaner at a $2 \%$ concentration. The washers were vented outdoors through the roof.

\section{Machining-wet grinding.}

Grey cast iron L850 camshafts are rough and finish ground on a Landis grinder using high-speed plated CBN wheels. BenzGrind HP15 straight oil is used on this one operation only for high performance cams. At the time of this study, only one grinder was in production mode on singleshift operation, producing about 450 cams per shift. The production grinder was totally enclosed and vented, along with several other machines, to a 12,000 CFM Monroe spiral tube mist collector. Other fluids in use on the cam line were Clearedge 6510, WS3-091A, Hysol X, Honilo 480 straight oil from Castrol, and Aquaquench 3600 hardener from Houghton. General ventilation was provided from air supply vents to the east and west of the area and by open windows in the saw-tooth roof.

\section{Machining - dry machining.}

Due to the internal lubricity provided by the high carbon content of cast iron, metal removal fluids are frequently unnecessary. Grey cast iron L35 engine blocks are machined on a transfer line consisting primarily of unenclosed Lamb machines. Some areas of the line had minienclosures with air draws. The line was running two-shift operation with approximately 1050 blocks machined per shift. Although not enclosed, hoods above the operations ducted the air to about eight different air cleaners throughout the area. Several overhead air vents also provided general ventilation.

\section{Heat treatment-carburizing furnace.}

Heat treatment is accomplished in a mostly-enclosed room containing both nitriding and carburizing operations. In carburizing, steel (5130 steel) is exposed to a carbon-containing gas at high temperatures, such that the carbon diffuses into the surface of the steel and forms carbides. Carburizing is used extensively on gears, sprockets, and shafts to build wear and fatigue resistance. Each of two carburizing furnaces consists of a circular line where parts are manually loaded onto metal trays. The furnace operates with a mixture of reaction gas (active ingredient is $\mathrm{CO}$ ) at a slightly positive pressure of $62.5 \mathrm{~Pa}$. The parts are heated to $1500^{\circ} \mathrm{F}$ or greater to 
achieve the desired diffusion of carbon into the steel surface. The parts exit the furnace between $1550^{\circ} \mathrm{F}$ and $1700^{\circ} \mathrm{F}$ and are quenched in $325^{\circ} \mathrm{F}$ oil quenchant for 3 minutes. The parts drain, are washed at $140^{\circ} \mathrm{F}$, and then go through a $325^{\circ} \mathrm{F}$ draw furnace to "draw back the temper." In addition to the carburizing furnace, reaction gas generators operate nearby. These reactors burn natural gas to produce a reaction gas: $40 \% \mathrm{~N}_{2}, 40 \% \mathrm{H}_{2}$, and $20 \% \mathrm{CO}$. The quenchant used is Quenchol 624 from Atlantic Richfield. Other chemicals used in the same area are Quench Q and Cerfa Kleen 5391 (Houghton International).

\section{Assembly - welding.}

Welding is a major industrial activity that involves up to $2 \%$ of the working population in industrialized nations. Two types of welding are used in this plant to join galvanized steel parts: resistance (spot) welding and a lesser amount of metal inert gas arc welding (MIG). Spot welding involves applying a high current between two copper electrodes mounted on either side of the parts to be joined. The resistance of the metals causes localized heating and melting of the metals such that a "nugget" of combined metal is formed in the melt region. MIG welding involves heating with an electric arc between a consumable electrode and the metal part. Shielding is provided with an inert gas, in this case argon/carbon dioxide. No liquid chemicals are used in the process although residual-forming oils could remain on the steel parts. Robots carried out all of the routine welding operations. Air supply houses above the welding operations provide area ventilation. Local exhaust ventilation was also provided for some welding operations, especially MIG. The local exhaust systems were ventilated by Torit cartridge filter type dust collectors and the air was recirculated into the plant.

\section{Assembly - paint ovens.}

A large area of 170,000 $\mathrm{ft}^{2}$ is devoted to paint ovens in this plant, which include ELPO ovens, primer/surfacer and sealer ovens, and basecoat/clearcoat ovens. In all cases, the car body slowly moves through 12-feet high by 10 -feet wide "oven tunnels" until the most recently applied coating has achieved the proper temperature and time for curing. Ten oven zones encompassed about 140 feet of oven length and 17,000 $\mathrm{ft}^{3}$ of volume. The ovens processed about $980 \mathrm{car}$ bodies per day. Air heated to $367^{\circ} \mathrm{F}$ enters the oven and is exhausted to the roof, where it passes 
through three catalytic incinerators to destroy volatile organic compounds. The area outside the ovens had only general plant ventilation. Few personnel were in the area.

\section{DESCRIPTION OF AEROSOL SAMPLING INSTRUMENTS}

Table S1. Aerosol sampling instruments

\begin{tabular}{|c|c|c|c|}
\hline Instrument & Type & Size range $(\mu \mathrm{m})$ & Purpose \\
\hline \multicolumn{4}{|l|}{ Area: Direct reading } \\
\hline TSI DustTrak & $\mathrm{RPA}^{\mathrm{a}}$ & $0.3-1.0$ & Mapping, temporal mass \\
\hline TSI DustTrak & RPA & $0.3-10$ & Mapping, temporal mass \\
\hline \multicolumn{3}{|l|}{ Sizer } & Real-time size dist/conc \\
\hline \multicolumn{4}{|l|}{ Area: Integrated } \\
\hline MOUDI & $\mathrm{CI}^{\mathrm{b}}$ & $0.06-20$ & Mass Distribution \\
\hline $\mathrm{PM}_{2.5}$ filter & $\mathrm{SS}^{\mathrm{c}}$ & $<2.5$ & $\begin{array}{l}\text { Mass Concentration, chemistry } \\
\text { (plant and background) }\end{array}$ \\
\hline \multicolumn{4}{|l|}{ Personal Collector $^{\mathrm{d}}$} \\
\hline 37-mm Closed Face & Filter & $<20$ & "Total Particulate Matter" \\
\hline
\end{tabular}

${ }^{a}$ RPA: Real-Time Particle Analyzer

${ }^{\mathrm{b}} \mathrm{CI}$ : Cascade impactor

${ }^{\mathrm{c}} \mathrm{SS}$ : Cyclone-type size-selective sampler

${ }^{\mathrm{d}}$ Traditional industrial hygiene sampler used as area sampler for this study 
Color palette for Figure 1: (A) Color palette used for $\mathrm{PM}_{10}$ and $\mathrm{PM}_{1.0}$ (B) Color palette used for particle count.

a)

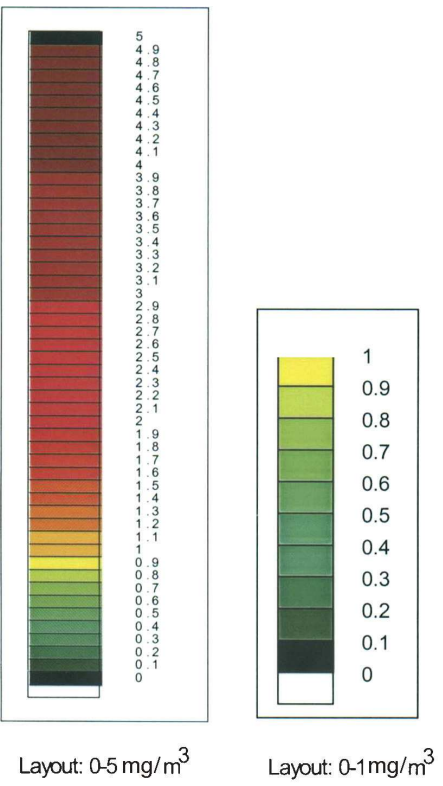

b)

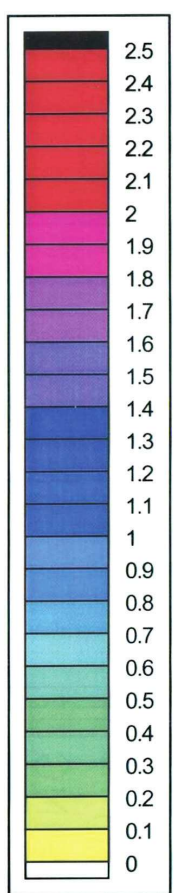

(\#Particles/cm3)/250,000

Process order for figures: $\mathrm{PM}_{10}$ maps, Temporal variations in $\mathrm{PM}_{10}$ and $\mathrm{PM}_{1.0}$, and Particle size distributions as determined with MOUDI

a) Iron foundry melt/pour

b) Iron foundry shakeout

c) Al lost foam

d) Al diecasting

e) Wet machining

f) Grinding with oil

g) Dry machining

h) Carburizing furnace

i) Body shop welding

j) Paint ovens 
a)

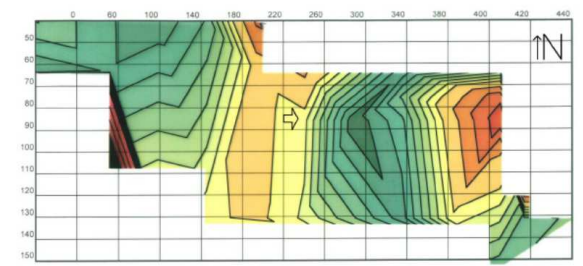

d)

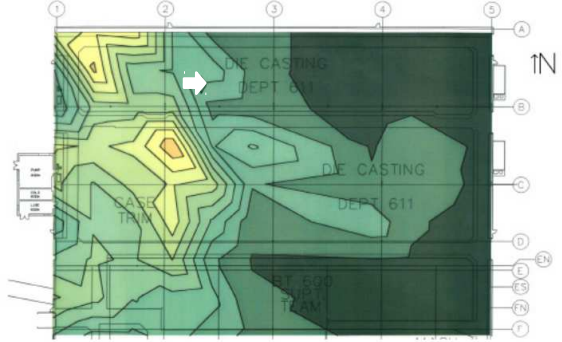

e)

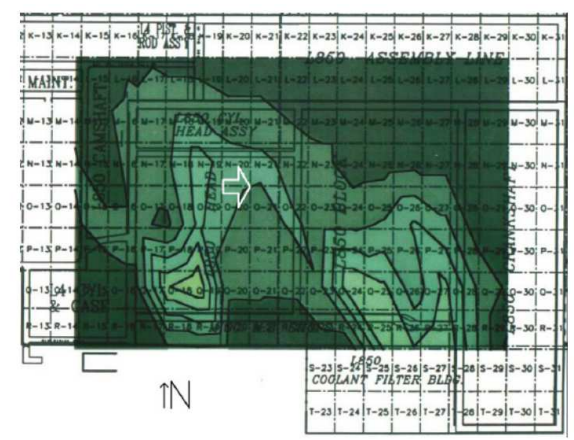

g)

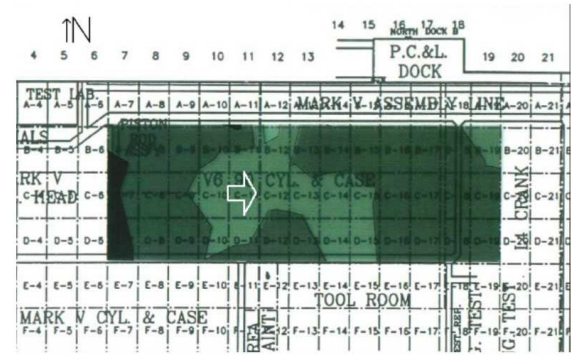

i)

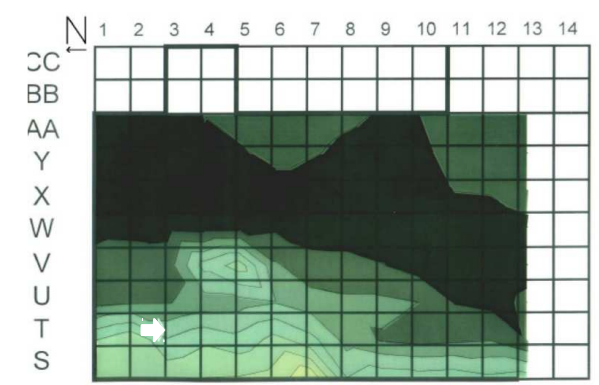

b)
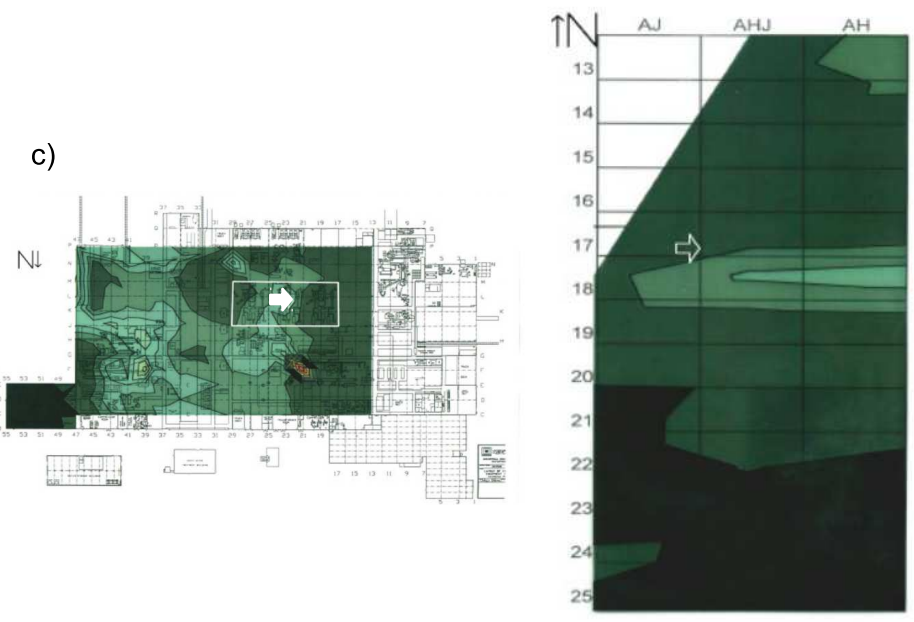

f)

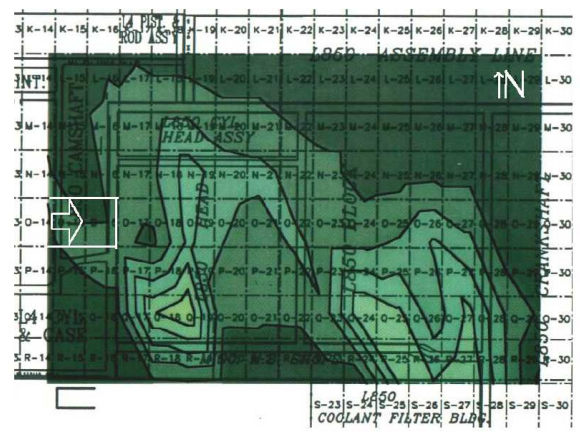

h)

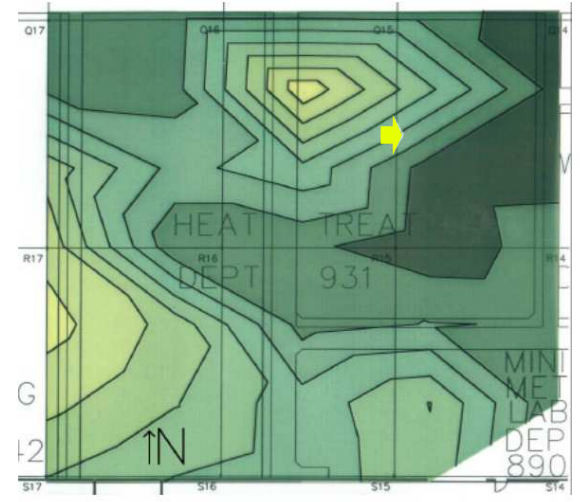

j)

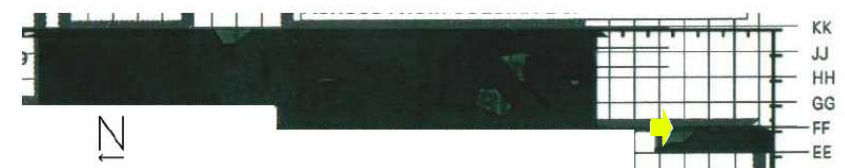

$\mathrm{PM}_{10}$ maps for ten manufacturing processes. The arrows indicate the site of intensive sampling. 
a)

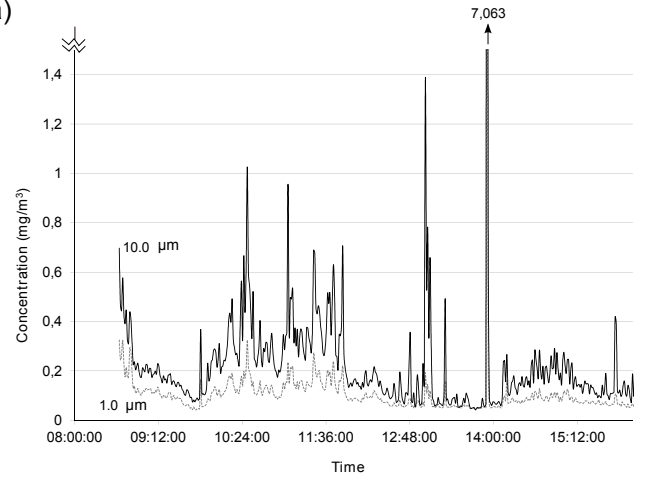

c)

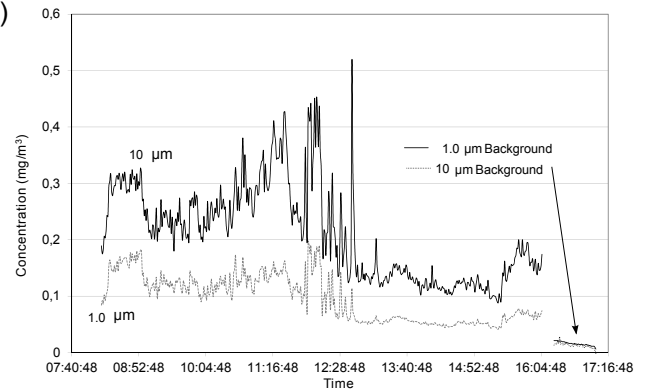

e)

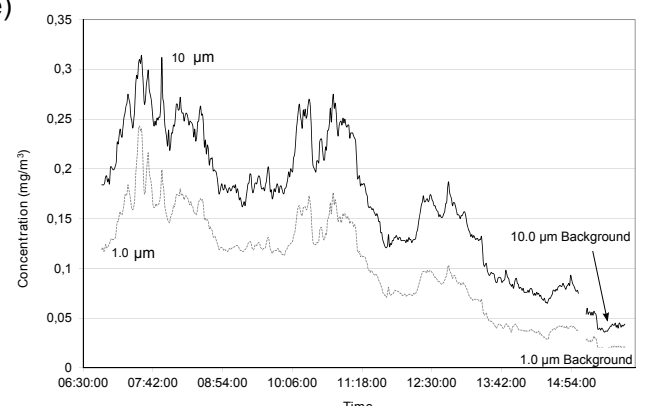

g)

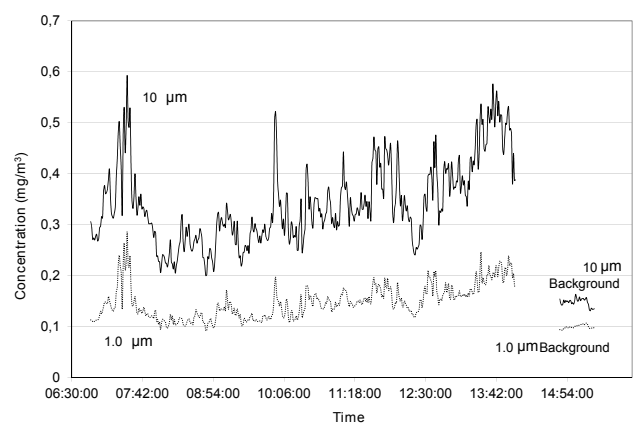

i)

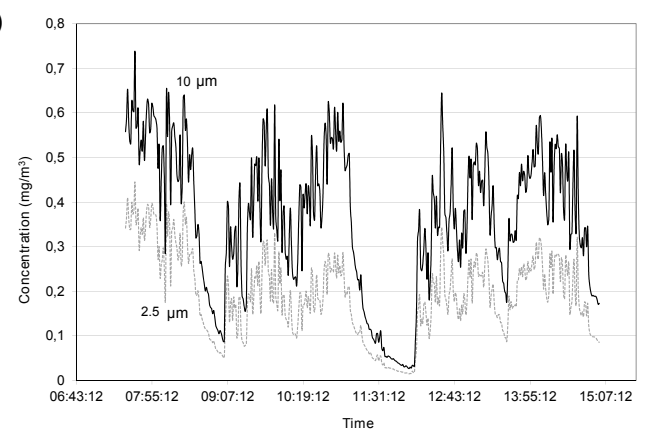

b)

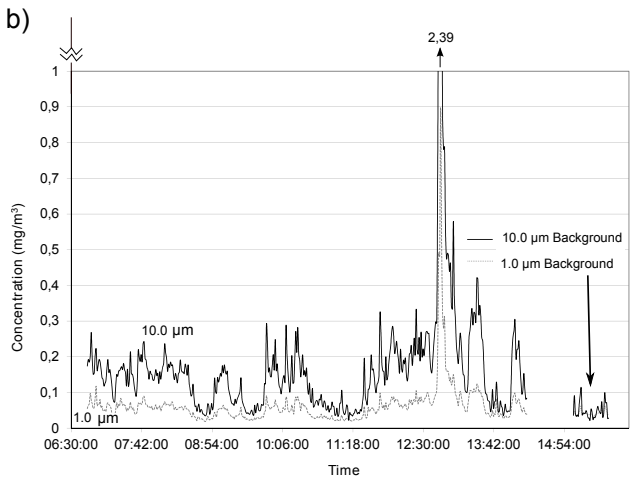

d)

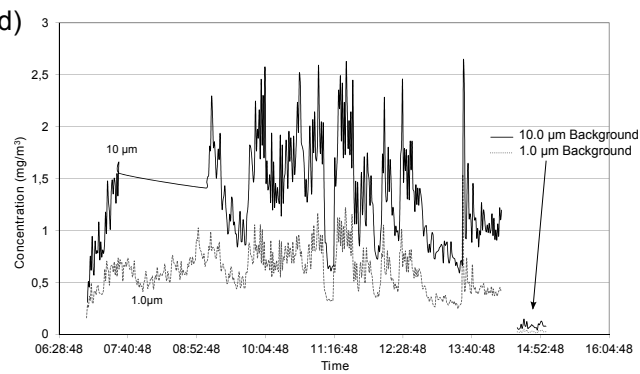

f)

h)
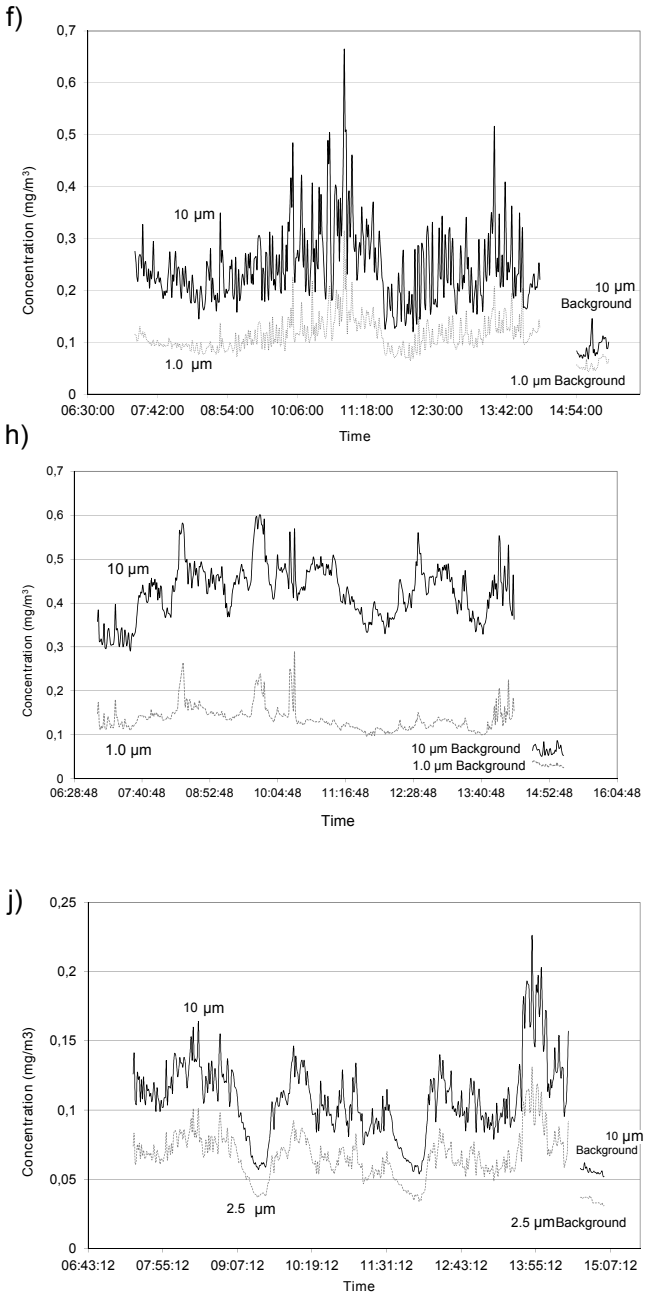

Temporal variations in $\mathrm{PM}_{10}$ and $\mathrm{PM}_{1.0}$ during intensive sampling of ten processes. 
a)

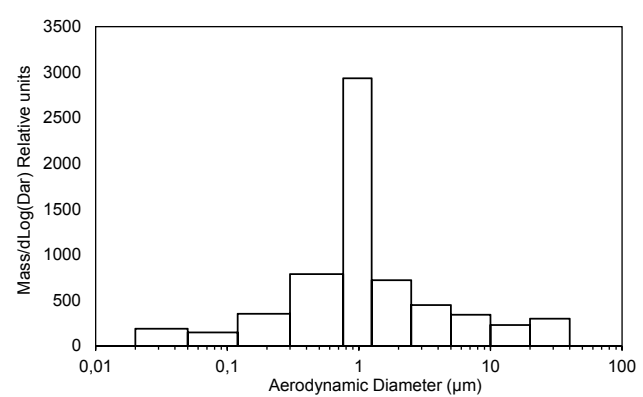

c)

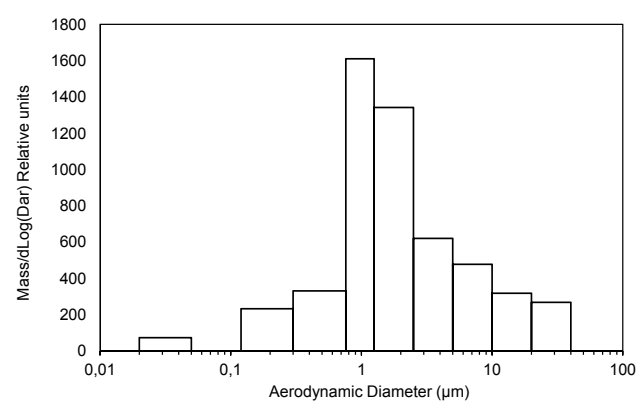

e)

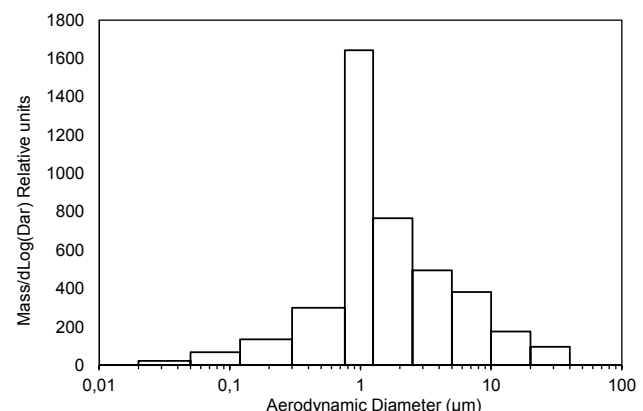

g)

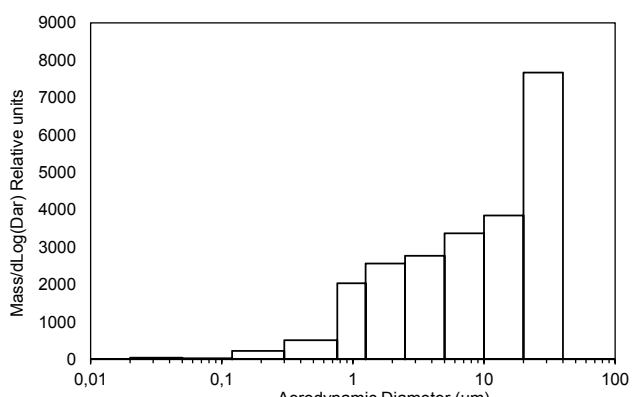

i)

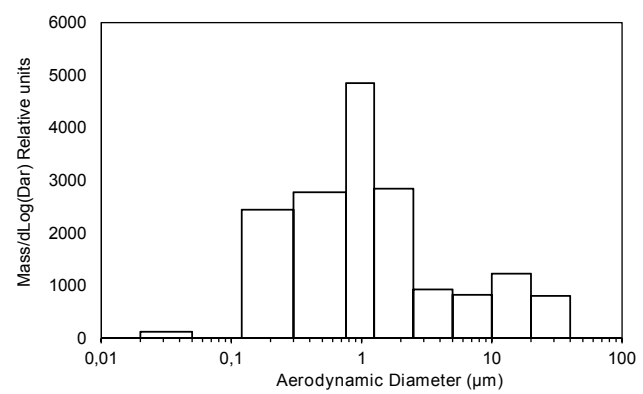

b)

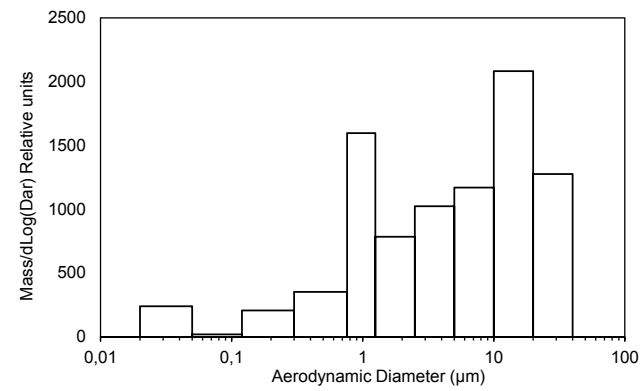

d)

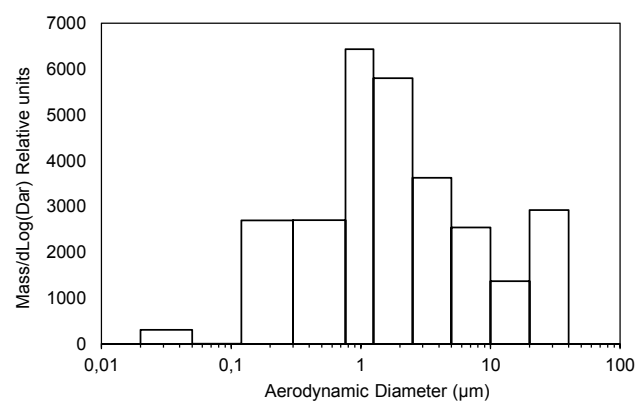

f)

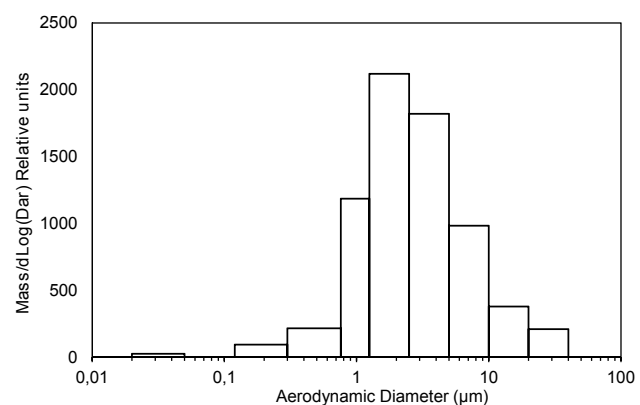

h)

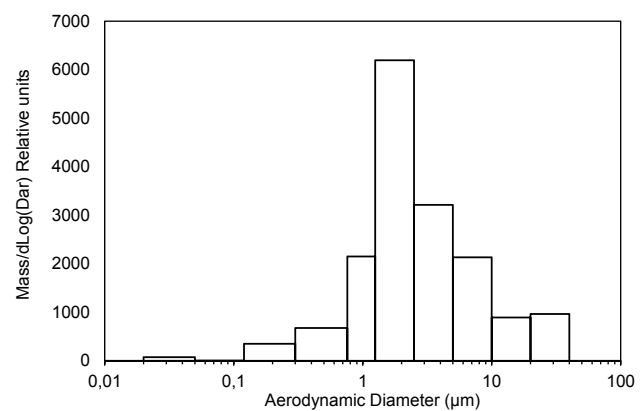

j)

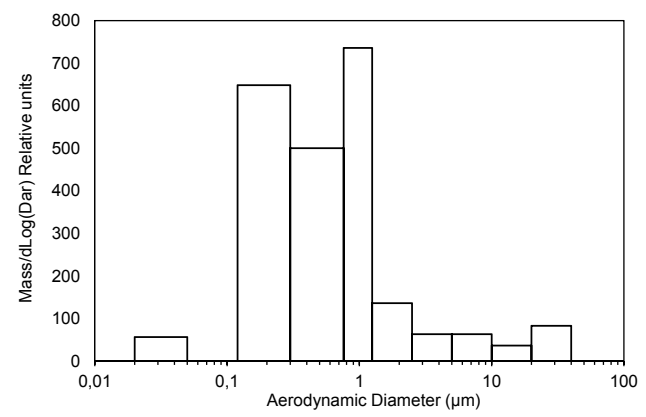

Particle size distributions as determined with MOUDI sampler for ten manufacturing processes. 